\title{
Status Mutu Air dan Sedimen Perairan Desa Sukolilo Kec. Labang Kabupaten Bangkalan
}

\author{
Indah Wahyuni Abida ${ }^{1,2}$, Sri Andayani ${ }^{3}$, Uun Yanuhar ${ }^{3}$, Hardoko $^{3}$
}

1. Staf Pengajar Manajemen Sumberdaya Perairan Universitas Trunojoyo

2. Mahasiswa Program Doktoral Pascasarjana FPIK Universitas Brawijaya

3. Staf Pengajar Program Pascasarjana FPIK Universitas Brawijaya

abid_utm@yahoo.com

\begin{abstract}
ABSTRAK
Kualitas perairan pesisir yang baik sangat penting dalam menunjang kehidupan organisme yang berada didalamnya. Adanya beban masukan dari daratan akan menyebabkan perubahan pada kualitas perairan baik pada badan air maupun pada dasar perairannya. Tujuan penelitian ini adalah untuk mengetahui status mutu air dan sedimen perairan Desa Sukolilo Kecamatan Labang Kabupaten Bangkalan. Metode penelitian menggunakan pengambilan data dengan metode purposive sampling dimana lokasi pengambilan sampel adalah area penangkapan kerang simping. Pengambilan sampel air dan sedimen dilakukan pada 3 titik di perairan desa Sukolilo Kec. Labang Kab. Bangkalan. Pengukuran parameter fisika kimia perairan dilakukan sesuai dengan prosedur yang berlaku. Status mutu air dan sedimen ditentukan dengan menghitung Indek Pencemaran berdasarkan Kepmen LH No.115 tahun 2003 dengan nilai baku mutu untuk biota laut berdasar pada Kepmen LH No.51 tahun 2004 dan CCME tahun 2002. Hasil penelitian menunjukkan bahwa nilai Indeks Pencemaran air berkisar 5,662-6,269 dengan status mutu tercemar sedang, sedangkan pada sampel sedimen mempunyai nilai Indeks Pencemaran berkisar 8,834-9,474 dengan status mutu tercemar sedang.
\end{abstract}

Kata Kunci: Status Mutu air, Indeks Pencemaran, Perairan Sukolilo 


\section{PENDAHULUAN}

Perairan pesisir sangat rentan terhadap pencemaran. Beban cemaran yang masuk langsung ataupun melalui sungai ke perairan baik organik maupun anorganik. Aktivitas manusia yang banyak menyumbangkan cemaran diantaranya adalah dari limbah domestik, aktivitas pertanian dan perikanan, pelayaran maupun industri. Aktivitas ini akan membawa dampak tersendiri bagi perairan yang dihuni oleh berbagai jenis organisme. Bagi organisme perairan, adanya perubahan lingkungan akibat beban pencemar akan berdampak pada fisiologi dan keberadaan organisme yang mendiami.

Penelitian Bachtiar (2008) menunjukkan tingginya nilai beban cemaran yang masuk ke Selat Madura rata-rata setiap tahunnya untuk BOD (Biological Oxigen Demand) sebanyak 1.634.681,61 ton/tahun, COD (Chemical Oxigen Demand) per tahun sebesar 2.407.614,75 ton/tahun dan TSS (Total Suspended Solid) per tahun sebesar 1.486.880,25 ton/tahun. Tingginya beban cemaran ini akan berdampak secara ekonomi dengan menurunnya nilai potensi biomass sumberdaya ikan yang ada didalamnya.

Perairan pesisir desa Sukolilo, kecamatan Labang, merupakan kawasan daerah pesisir selatan kabupaten Bangkalan yang sebagian besar penduduknya adalah nelayan. Perairan yang masuk dalam kawasan selat Madura sisi sebelah barat ini mempunyai kondisi topografi yang mulai menyempit sehingga dengan pola arus yang terjadi di perairan, akan menyebabkan penyebaran cemaran perairan yang berasal dari perairan disekitarnya. Dimana perairan sekitar merupakan kawasan perairan dengan beban cemaran yang tinggi akibat industri, pelayaran dan domestik yaitu kawasan Surabaya, Sidoarjo, Pasuruan dan Gresik.

Wilayah perairan ini
merupakan kawasan daerah
penangkapan ikan yang termasuk
didalamnya adalah komoditas
Kerang-kerangan yang hidupnya
sesil di dasar perairan. Kualitas air
dan sedimen yang baik akan
menentukan keberadaan dari
organisme yang menghuni
didalamnya. Tujuan dari penelitian
ini adalah untuk mengetahui status
mutu air dan sedimen pada perairan
desa Sukolilo Kecamatan Labang
Kabupaten Bangkalan.

\section{METODE PENELITIAN}

Pengambilan Sampel

Penelitian ini dilakukan dengan mengambil sampel air dan sedimen ditentukan secara Purposive sampling, dimana perairan ini merupakan tempat penangkapan kerang-kerangan oleh nelayan. Pengambilan sampel dilakukan pada bulan Nopember 2017 dengan diambil 3 titik sampling dengan jarak $\pm 700 \mathrm{~m}$. Lokasi dan titik sampling pengambilan sampel tersebut dapat dilihat pada Gambar 1. dan Tabel 1. berikut :

Tabel 1. Lokasi pengambilan sampel

\begin{tabular}{lll}
\hline Titik & Lintang selatan & Bujur Timur \\
\hline $\mathbf{1}$ & $07^{\circ} 09^{\prime} 44.28^{\prime \prime}$ & $112^{\circ} 48^{\prime} 03.03^{\prime \prime}$ \\
$\mathbf{2}$ & $07^{\circ} 09^{\prime} 45.70^{\prime \prime}$ & $112^{\circ} 48^{\prime} 07.61^{\prime \prime}$ \\
$\mathbf{3}$ & $07^{\circ} 09^{\prime} 46.87^{\prime \prime}$ & $112^{\circ} 48^{\prime} 14.966^{\prime \prime}$ \\
\hline
\end{tabular}

Pengambilan sampel air pada titik pengambilan dilakukan dengan alat vandorm water sampler, sedangkan untuk sampel sedimen 
diambil dengan menggunakan alat Eckman grab. Parameter yang diukur meliputi parameter fisika dan kimia air dan sedimen. Pengukuran parameter ini ada yang dilakukan dengan insitu (suhu, pH, kecerahan, salinitas dan oksigen terlarut) dan exsitu (logam berat, $\mathrm{NH}_{3}, \mathrm{NO}_{3}, \mathrm{PO}_{4}$, BOD dan COD). Sampel air yang terambil dimasukkan pada botol sampel yang berbeda dan diawetkan sesuai dengan tujuan analisa berdasarkan SNI 6989.59:2008. Sampel diberi pengawet $\mathrm{HNO}_{3}$ untuk analisa logam berat, pengawet $\mathrm{H}_{2} \mathrm{SO}_{4}$ untuk analisa ammonia $\left(\mathrm{NH}_{3}\right)$ dan nitrat $\left(\mathrm{NO}_{3}\right)$, dan tanpa penambahan bahan pengawet untuk analisa Total Suspended Solid (TSS), orthophospat $\left(\mathrm{PO}_{4}\right)$, BOD (Biological Oxygen Demand), COD (Chemical Oxygen Demand). Untuk sampel sedimen yang terambil langsung dimasukkan ke plastik sampel yang telah diberi label, kemudian semua sampel dimasukkan dalam coolbox pada suhu $4^{\circ} \mathrm{C}$ dan dibawa ke Laboratorium Lingkungan dan Kualitas air Universitas Trunojoyo Madura dan Laboratorium Kimia Universitas Brawijaya untuk dilakukan analisa kualitas air dan sedimen.

\section{Analisa data}

Hasil pengukuran yang didapatkan dari laboratorium akan ditabulasi dan dideskripsikan. Untuk menentukan status mutu air dan sedimen akan dihitung dengan menggunakan metode Indeks Pencemaran yang perhitungannya berdasarkan Keputusan Menteri Negara Lingkungan Hidup No. 115 tahun 2003 tentang Pedoman Penentuan Status Mutu Air, dengan menggunakan nilai baku mutu air laut yang ditetapkan oleh Menteri Negara Lingkungan Hidup No. 51 tahun 2004 untuk biota laut. Nilai Indeks Pencemaran ini juga digunakan untuk menghitung Status mutu sedimen, dimana perhitungan ini dimaksudkan untuk melihat seberapa besar tingkat mutu sedimen yang merupakan tempat hidup dari organisme sesil didasar perairan (makrozoobenthos). Nilai baku mutu yang digunakan untuk perhitungan logam berat didasarkan pada Canadian Sediment Quality Guidelines for The Protection of Aquatic Life yang dirilis oleh Kementerian Lingkungan Hidup Kanada (Canada Council of Minister of Environment, CCME) pada tahun 2002 karena di Indonesia belum ada ketetapan tentang baku mutu sedimen untuk biota laut.

Adapun persamaan nilai Indeks Pencemaran (Plj) yang digunakan adalah :

$$
\mathrm{Plj}=\sqrt{\frac{\left(\mathrm{C}_{\mathrm{i}} / \mathrm{L}_{\mathrm{ij}}\right)_{\mathrm{M}}^{2}+\left(\mathrm{C}_{\mathrm{i}} / \mathrm{L}_{\mathrm{ij}}\right)_{\mathrm{R}}^{2}}{2}}
$$

Dimana :

$(\mathrm{Ci} / \mathrm{Lij}) \mathrm{M}=$ Nilai rata-rata dari jumlah konsentrasi parameter yang diuji

$(\mathrm{Ci} / \mathrm{Lij}) \mathrm{R}=$ Nilai maksimal dari hasil pembagian hasil konsentrasi dengan nilai baku mutu

Evaluasi hasil dari Indeks Pencemaran adalah:

$0<\mathrm{Plj}<1=$ memenuhi baku mutu (kondisi baik)

$1<\mathrm{Plj}<5=$ tercemar ringan 


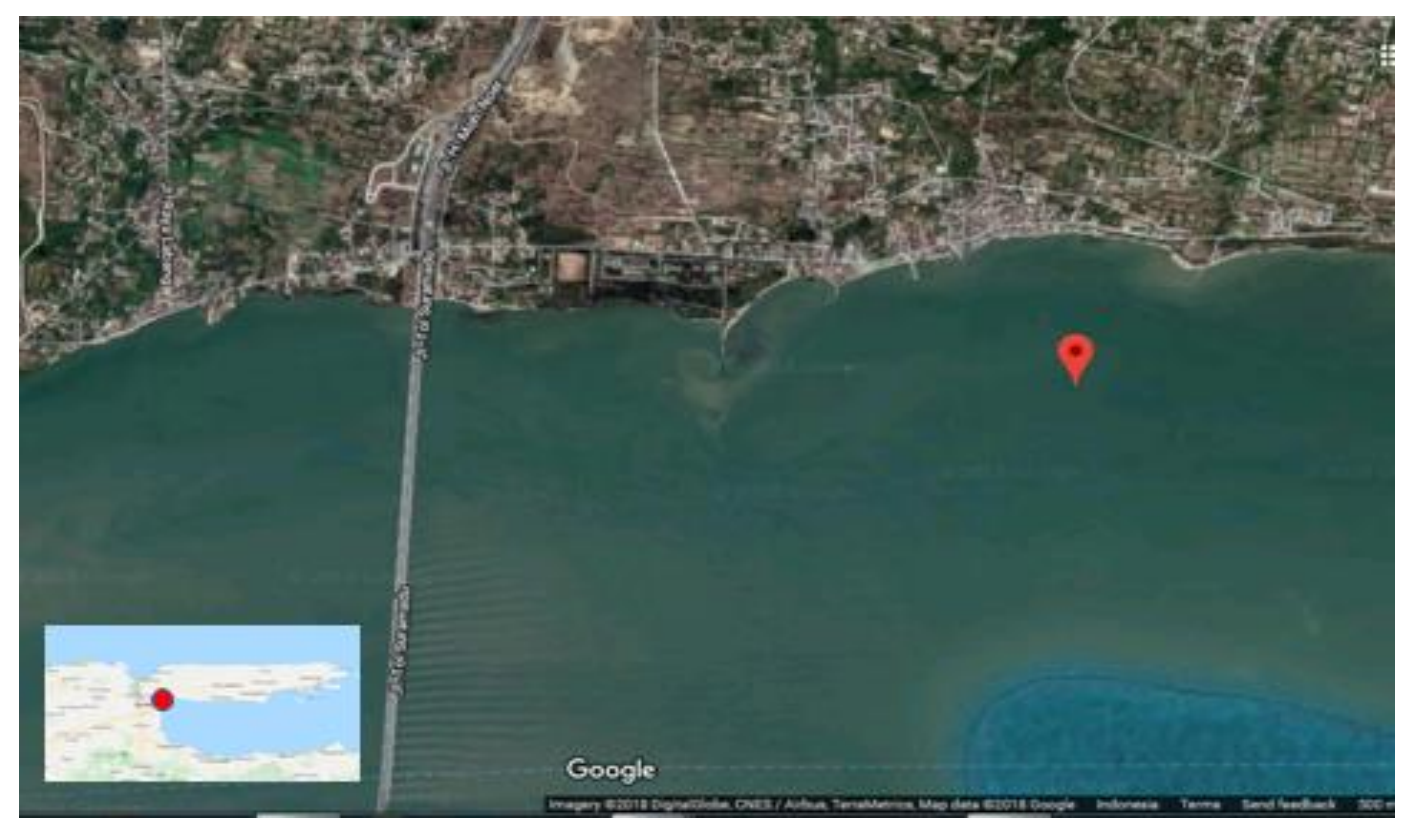

Sumber: googleearth, (2018)

Gambar 1. Peta lokasi pengambilan sampel

Tabel 2. Hasil pengukuran kualitas air

\begin{tabular}{lrrrc}
\hline \multicolumn{1}{c}{ Parameter } & \multicolumn{3}{c}{ Stasiun } & \multicolumn{2}{c}{$\begin{array}{c}\text { Baku Mutu KLH No 51 } \\
\text { th 2004 }\end{array}$} \\
\hline Suhu $\left({ }^{\circ} \mathrm{C}\right)$ & 31,2 & 31,3 & 31,5 & Alami \\
Kecerahan $(\mathrm{cm})$ & 13 & 17 & 15 & Alami \\
Salinitas $(\%)$ & 26 & 27 & 29 & Alami \\
$\mathrm{pH}$ & 7,4 & 7,3 & 7,3 & $7-8,5$ \\
$\mathrm{DO}(\mathrm{mg} / \mathrm{L})$ & 5,24 & 5,27 & 5,35 & $>5$ \\
$\mathrm{BOD}(\mathrm{mg} / \mathrm{L})$ & 23 & 25 & 18 & 20 \\
$\mathrm{COD}(\mathrm{mg} / \mathrm{L})$ & 32 & 24 & 28 & - \\
$\mathrm{TSS}(\mathrm{mg} / \mathrm{L})$ & 27 & 24 & 31 & 20 \\
$\mathrm{TOM}(\mathrm{mg} / \mathrm{l})$ & 13 & 11 & 16 & - \\
$\mathrm{NO}(\mathrm{mg} / \mathrm{L})$ & 0,85 & 0,55 & 0,73 & 0,006 \\
$\mathrm{PO}(\mathrm{mg} / \mathrm{L})$ & 0,43 & 0,52 & 0,35 & 0,015 \\
$\mathrm{NH}{ }_{3}(\mathrm{mg} / \mathrm{L})$ & 0,56 & 0,69 & 0,45 & 0,3 \\
$\mathrm{Zn}(\mathrm{mg} / \mathrm{L})$ & 0,0051 & 0,0058 & 0,0036 & 0,05 \\
$\mathrm{Hg}(\mathrm{mg} / \mathrm{L})$ & 0,0025 & 0,0016 & 0,0016 & 0,001 \\
$\mathrm{Cd}(\mathrm{mg} / \mathrm{L})$ & 0,0021 & 0,0007 & 0,0014 & 0,001 \\
$\mathrm{Fe}(\mathrm{mg} / \mathrm{L})$ & 0,0407 & 0,0465 & 0,0291 & - \\
$\mathrm{Pb}(\mathrm{mg} / \mathrm{L})$ & 0,007 & 0,0075 & 0,0046 & 0,008 \\
$\mathrm{Cr}(\mathrm{mg} / \mathrm{L})$ & 0,0006 & 0,0008 & 0,0005 & 0,005 \\
$\mathrm{Cu}(\mathrm{mg} / \mathrm{L})$ & 0,0253 & 0,019 & 0,0221 & 0,008 \\
\hline $\mathrm{Sumber}$ & & & &
\end{tabular}

Sumber: Data primer diolah, 2018 
Tabel 3. Hasil pengukuran kualitas sedimen

\begin{tabular}{|c|c|c|c|c|}
\hline \multirow{2}{*}{ Parameter } & \multicolumn{3}{|c|}{ Stasiun } & \multirow{2}{*}{$\begin{array}{l}\text { Baku Mutu } \\
\text { 1. KLH No } 51 \text { th } 2004 \\
\text { 2. CCME th } 2002\end{array}$} \\
\hline & 1 & 2 & 3 & \\
\hline $\mathrm{BOD}(\mathrm{mg} / \mathrm{Kg})$ & 37 & 42 & 32 & 201 \\
\hline $\operatorname{COD}(\mathrm{mg} / \mathrm{Kg})$ & 52 & 48 & 60 & - \\
\hline $\mathrm{PO}_{4}(\mathrm{mg} / \mathrm{Kg})$ & 3,62 & 2,71 & 4,07 & 0,015 \\
\hline $\mathrm{NH}_{3}(\mathrm{mg} / \mathrm{Kg})$ & 14,11 & 8,1 & 12,33 & 0,3 \\
\hline $\mathrm{Zn}(\mathrm{mg} / \mathrm{Kg})$ & 0,0897 & 0,0719 & 0,0989 & $124^{(2}$ \\
\hline $\mathrm{Hg}(\mathrm{mg} / \mathrm{Kg})$ & 0,0204 & 0,0102 & 0,0204 & $0,13^{2}$ \\
\hline $\mathrm{Cd}(\mathrm{mg} / \mathrm{Kg})$ & 0,0089 & 0,0178 & 0,0089 & 0,7 \\
\hline $\mathrm{Pb}(\mathrm{mg} / \mathrm{Kg})$ & 0,0864 & 0,0577 & 0,0721 & $30,2^{(2}$ \\
\hline $\mathrm{Cr}(\mathrm{mg} / \mathrm{Kg})$ & 0,0118 & 0,0131 & 0,0099 & $52,3^{2}$ \\
\hline $\mathrm{Cu}(\mathrm{mg} / \mathrm{Kg})$ & 0,8767 & 0,6859 & 0,801 & $18,7^{(2}$ \\
\hline $\mathrm{pH}$ & 6,83 & 6,95 & 6,88 & $6-8,5^{(1}$ \\
\hline $\mathrm{N}(\%)$ & 0,12 & 0,14 & 0,1 & - \\
\hline C (\%) & 1,46 & 1,63 & 1,31 & - \\
\hline $\mathrm{C} / \mathrm{N}$ ratio & 12,17 & 11,64 & 13,1 & - \\
\hline
\end{tabular}

Sumber: Data Primer Diolah, 2018

$5<\mathrm{Plj}<10=$ tercemar sedang

$\mathrm{Plj}>10=$ tercemar berat

\section{HASIL DAN PEMBAHASAN}

Kualitas Air

Hasil pengukuran kualitas air didapatkan seperti pada tabel 2 . dibawah ini. Berdasarkan tabel 2 diatas menunjukkan beberapa nilai yang sudah sesuai dengan baku mutu air laut yang ditetapkan untuk kebutuhan biota laut diantaranya suhu, salinitas, $\mathrm{pH}$ dan oksigen terlarut. Nilai kecerahan meskipun di dalam baku mutu tidak ada nilainya tetapi nilai yang berkisar antara $13-17 \mathrm{~cm}$ tergolong nilai yang rendah, dimana nilai ini akan mengakibatkan menurunnya penetrasi cahaya yang dibutuhkan oleh fitoplankton untuk berfotosintesis. Rendahnya nilai kecerahan ini diakibatkan resuspensi sedimen akibat pola arus sehingga kekeruhan perairan meningkat, hal ini dapat dilihat dari nilai TSS (Total Suspended Solid) yang relatif tinggi diatas nilai ambang batas baku mutu KepMen LH No.51 tahun 2004. Penelitian Abida (2008) juga menunjukkan nilai kecerahan perairan di kawasan perairan selatan Bangkalan yang rendah akibat dipengaruhi oleh padatan tersuspensi.

Seperti hasil penelitian Bachtiar (2008) diatas, nilai TSS menunjukkan nilai yang terbesar dalam mempengaruhi kondisi biomassa ikan sehingga akan mempengaruhi juga depresiasi nilai ekonomi sumberdaya perikanan yang ada di Selat Madura. Hal ini karena Total Suspended Solid atau total padatan tersuspensi merupakan material organik maupun anorganik yang berasal dari buangan limbah industri, pemukiman maupun dari erosi tanah yang terkena limpasan air yang akan mempengaruhi laju fotosintesis fitoplankton sebagai produsen primer di perairan.

Parameter perairan yang mempunyai nilai lebih tinggi dari baku 
mutu air untuk biota laut adalah kandungan nitrat, orthoposphat, amonia dan logam berat Cadmium dan $\mathrm{Hg}$. Tingginya nilai nutrien amonium, dan nitrat ini lebih banyak dipengaruhi oleh proses dekomposisi bahan organik yang terdapat pada kolom perairan. Hal ini juga dapat dilihat dari nilai TOM (Total Organic Matter) yang berkisar antara 11-16 mg/L. Abida (2010) menyatakan bahwa adanya masukan bahan organik dari limbah domestik pemukiman penduduk dan proses recycled akan meningkatkan nilai amonium pada kolom perairan. Hal ini karena lokasi pengambilan sampel ini merupakan perairan yang berbatasan dengan daratan.

Parameter logam berat hasil dari pengukuran menunjukkan kadar logam berat $\mathrm{Cr}, \mathrm{Pb}$ dan $\mathrm{Zn}$ mempunyai konsentrasi dibawah nilai ambang batas baku mutu air untuk biota laut, sedangkan konsentrasi logam berat $\mathrm{Hg}$ dan $\mathrm{Cd}$ mempunyai nilai diatas nilai baku mutu yang ditetapkan KepMen LH No. 51 tahun 2004 untuk biota laut. Hasil penelitian yang dilakukan oleh Taftazani (2007) juga menunjukkan kadar logam $\mathrm{Hg}$ dan $\mathrm{Cr}$ pada sampel air laut di lokasi pengamatan muara sungai yang ada di kota Surabaya mempunyai nilai yang lebih besar dari batas ambang dari Kepmen LH No. 51/2004 yaitu Hg sebesar $0,001 \mathrm{mg} / \mathrm{L}$ dan $\mathrm{Cr} 0,005 \mathrm{mg} / \mathrm{L}$.

Tingginya nilai logam berat ini akibat perairan Sukolilo merupakan perairan Selat Madura yang berada di sisi sebelah barat dimana topografi yang mulai menyempit menyebabkan pola arus yang ada akan membawa material material buangan dari daratan yang berada di kawasan selat Madura. Kawasan selat Madura merupakan selat yang banyak bermuara sungai sungai dari kawasan industri baik dari Surabaya, Sidoarjo, Pasuruan maupun Probolinggo dan hal ini menyebabkan perairan banyak menerima buangan industri maupun buangan limbah domestik.

\section{Kualitas Sedimen}

Dasar perairan memegang
peranan penting untuk menopang kehidupan organisme bentik seperti bivalvia, krustacea maupun zoobenthos lainnya. Hasil pengukuran parameter kimia sedimen dapat dilihat pada tabel 3. Hasil analisa pada tabel 3 diatas apabila dibandingkan dengan baku mutu air KepMen LH No 51 tahun 2004 menunjukkan bahwa parameter kimia $\mathrm{BOD}, \mathrm{COD}, \mathrm{PO}_{4}, \mathrm{NH}_{3}$, tersebut lebih tinggi dari baku mutu air yang ditentukan. Sedangkan untuk nilai logam berat yang didasarkan pada nilai baku mutu CCME tahun 2002 mempunyai nilai dibawah nilai ambang baku. Nilai kandungan beberapa jenis logam berat ini lebih tinggi daripada nilai yang didapatkan di badan airnya. Hal ini karena sedimen mempunyai kemampuan akumulasi bahan kimia akibat dari penenggelaman materialmaterial yang ada pada kolom perairan. Dasar perairan dengan berbagai macam jenis substrat akan membentuk tekstur yang berbeda-beda. Jenis substrat yang berbeda akan mampu mengakumulasi logam berat yang berbeda.

Bila dibandingkan dengan hasil penelitian Abida et al. (2018) perairan Socah dan Bangkalan yang juga sebagai area penangkapan kerang Simping (Placuna placenta) menunjukkan bahwa parameter logam $\mathrm{Fe}$ dan $\mathrm{Cu}$ mempunyai nilai yang lebih tinggi dari perairan Desa Sabiyan Kec. Bangkalan dan Desa Junganyar Kec. Socah, sedangkan untuk parameter logam berat $\mathrm{Zn}, \mathrm{Pb}, \mathrm{Cd}, \mathrm{Cr}$ dan $\mathrm{Hg}$ mempunyai nilai rendah dari perairan Desa Sabiyan Kec. Bangkalan dan Desa Junganyar Kec. Socah. Nilai $\mathrm{pH}$ sedimen perairan Sukolilo lebih rendah dari perairan Desa Sabiyan tetapi lebih tinggi dari sedimen perairan Desa Junganyar Socah. Jika dibandingkan dengan hasil penelitian Simbolon et al.,(2014) di perairan pesisir Kabupaten Tangerang, maka didapatkan nilai logam berat di perairan desa Sukolilo ini 
menunjukkan nilai kandungan yang lebih rendah. Palar (2012) menyatakan bahwa logam berat yang masuk perairan akan segera berasosiasi dengan partikel sedimen dan terakumulasi didasar perairan sehingga logam berat yang ada di sedimen kandungannya lebih tinggi dari logam berat yang ada di air. Akumulasi logam berat dari air permukaan ke dasar perairan dipengaruhi oleh beberapa faktor lingkungan seperti kekuatan ion, $\mathrm{pH}$, masukan limbah antropogenik, jenis dan konsentrasi ligand organik dan inorganik.

Nilai BOD dan COD sedimen pada lokasi ini, jika dibandingkan dengan hasil penelitian Abida et al (2018) mempunyai nilai yang lebih rendah yaitu masing-masing berkisar $32-42 \mathrm{mg} / \mathrm{Kg}$ dan $48-60 \mathrm{mg} / \mathrm{Kg}$, dari sedimen perairan desa Junganyar Kecamatan Socah yang masing-masing sebesar 41-49 mg/Kg dan 58-72 mg/Kg, sedangkan sedimen perairan desa Sabiyan masing-masing sebesar 59-68 $\mathrm{mg} / \mathrm{l}$ dan $80-84 \mathrm{mg} / \mathrm{Kg}$. Hal ini menunjukkan perairan desa Sukolilo kondisi perairannya masih lebih baik bila dibandingkan dengan area penangkapan kerang desa Junganyar dan desa Sabiyan Kabupaten Bangkalan.

Nilai $\mathrm{C} / \mathrm{N}$ rasio yang diukur untuk mengetahui kadar karbon organik dan nitrogen yang ada pada substrat dapat dijadikan sebagai gambaran ketersediaan nutrien yang ada. Pada sedimen perairan desa Sukolilo sebesar 11,64-13,1, nilai ini lebih tinggi dari perairan desa Junganyar yang sebesar 7,53-10,58 dan lebih rendah dari perairan desa Sabiyan kecamatan Bangkalan yang sebesar 10,08-14,58 (Abida et al, 2018). Besar kecilnya nilai $\mathrm{C} / \mathrm{N}$ rasio disebabkan adanya pasokan karbon organik yang masuk ke perairan baik dari bahan organik limbah pemukiman maupun disumbang oleh ekosistem mangrove yang ada dikawasan tersebut. Keberadaan karbon organik dan nitrogen organik yang tinggi akan menyediakan lebih banyak nutrien bagi organisme yang hidup didalamnya.

Indeks Pencemaran Air dan Sedimen Status mutu perairan dapat dilihat dari nilai indeks pencemaran Perairan. Hasil perhitungan nilai Indeks Pencemaran berdasarkan Keputusan Menteri Lingkungan Hidup No 115 tahun 2003 didapatkan nilai seperti pada tabel 4.berikut.

Perhitungan nilai indeks pencemaran ini menggunakan nilai baku mutu air untuk biota laut, yang ditetapkan oleh Keputusan Menteri Lingkungan Hidup no 51 tahun 2004 dan CCME tahun 2002. Hasil perhitungan menunjukkan bahwa status mutu perairan desa Sukolilo tergolong pada perairan yang tercemar sedang untuk airnya, dan juga sedimennya. Bila dibandingkan dengan hasil penelitian yang dilakukan oleh Darmawan dan Masduqi (2014) yang melakukan penghitungan nilai indeks pencemaran dengan metode yang sama pada air di daerah pesisir Kabupaten Tuban dengan parameter TSS dan kimia non logam menghasilkan nilai yang lebih tinggi yaitu kisaran nilai antara 7,761-8,105, sedngkan di lokasi penelitian nilainya berkisar antara 5,622-6,269 untuk air dan 8,834-9,474 untuk sedimen.

Tabel 4. Nilai Indeks Pencemaran air dan sedimen

\begin{tabular}{ccccc}
\hline Sampel & $\mathbf{1}$ & $\mathbf{2}$ & $\mathbf{3}$ & Status \\
\hline Air & 5,975 & 6,269 & 5,662 & $\begin{array}{c}\text { Tercemar } \\
\text { sedang }\end{array}$ \\
Sedimen & 9,297 & 8,834 & 9,474 & $\begin{array}{c}\text { Tercemar } \\
\text { sedang }\end{array}$ \\
\multicolumn{2}{c}{$\begin{array}{c}\text { Sumber: Data primer diolah, 2018 } \\
\text { Simbolon }\end{array}$} & (2016) & yang
\end{tabular}

menghitung indeks pencemaran dengan metode STORET pada perairan Cilincing Pesisir DKI Jakarta tergolong tercemar sedang dengan nilai BOD, COD dan DO yang sudah melewati nilai ambang batas untuk keperluan organisme laut. Nilai Indeks pencemaran pada sedimen 
menunjukkan nilai yang lebih tinggi meskipun masih dalam kategori yang sama yaitu tingkat tercemar sedang. Hal ini disebabkan sedimen mampu mengakumulasi logam berat yang ada pada perairan akibat dari persenyewaan antara hidroksida dengan partikelpartikel yang ada pada badan air yang akhirnya mengendap dan membentuk lumpur di dasar perairan.

\section{DAFTAR PUSTAKA}

Abida I.W., (2008). Produktivitas Primer Fitoplankton Dan Keterkaitannya Dengan Intensitas Cahaya Dan Ketersediaan Nutrien Di Perairan Pantai Selat Madura Kabupaten Bangkalan. Tesis. Bogor, Indonesia: Program Sudi Magister IImu Perairan, Program Pascasarjana Institut Pertanian Bogor.

Abida I.W., (2010). Struktur Komunitas Dan Kelimpahan Fitoplankton Di Perairan Muara Sungai Porong Sidoarjo. Jurnal Kelautan. Vol.3 No $1,36-40$

Abida I.W., Andayani S., Yanuhar U. Dan Hardoko. 2018. Kualitas Air Dan Sedimen Pada Habitat Kerang Simping (Placuna placenta) Di Daerah Penangkapan Kabupaten Bangkalan. Prosiding Semnas Biologi Inovasi pendidikan dan Penelitian UNESA.

Bahtiar R. (2008). Penilaian Depresiasi Sumberdaya Perikanan di Selat Madura Propinsi Jawa Timur. https://repository.ipb.ac.id/bitstream/ handle/123456789/10595/2008rba1

Canadian Council of Ministers of the Environment. 2002. Canadian sediment quality guidelines for the protection of aquatic life. Canadian Environmental Quality Guidelines, Canada

\section{SIMPULAN DAN REKOMENDASI}

Hasil perhitungan nilai indeks pencemaran berdasar Kepmen LH No. 115 tahun 2003 dengan nilai baku mutu air laut untuk biota laut (Kepmen LH No 51 tahun 2004 dan CCME tahun 2002) didapatkan status mutu air laut dan sedimen di perairan desa Sukolilo Kec. Labang menunjukkan perairan yang tercemar sedang.

Darmawan H. dan Masduqi A., (2014). Indeks Pencemaran Air Laut Pantai Utara Tuban dengan Parameter Tss dan Kimia Non-Logam. Jurnal Teknik Pomits Vol. 3, No. 1,

MNLH. (2003). Keputusan Menteri Negara Lingkungan Hidup Nomor 115 Tahun 2003 tentang Pedoman Penentuan Status Mutu Air. JakartaIndonesia: Menteri Negara Lingkungan Hidup.

MNLH. (2004). Keputusan Menteri Negara Lingkungan Hidup Nomor 51 Tahun 2004 tentang Baku Mutu Air Laut. Jakarta-Indonesia: Menteri Negara Lingkungan Hidup.

Palar, H. (2012). Pencemaran dan Toksikologi Logam Berat. Rineka Cipta.

Simbolon A.R., (2016). Status Pencemaran di Perairan Cilincing, Pesisir DKI Jakarta. Proceeding Biology Education Conference (ISSN: 25285742), Seminar Nasional XIII Pendidikan Biologi FKIP UNS Vol 13(1) 2016: 677-682

Simbolon A.R., Riani, E. dan Wardiatno, Y. (2014). Status Pencemaran dan kandungan logam berat pada Simping (Placuna placenta) di pesisir Kabupaten Tangerang. Jurnal Depik 3(2): 91-98

Taftazani, A. (2007). Distribusi Konsentrasi Logam Berat $\mathrm{Hg}$ Dan $\mathrm{Cr}$ Pada Sampel Lingkungan Perairan Surabaya, Prosiding PPI-PDIPTN Pustek Akselerator dan Proses Bahan-BATAN ISSN 0216-3128; hal. 36-45. 